\title{
Digital Preservation of Electronic Records in the Croatian State Archives, U.S. National Archives and Records Administration and Library and Archives Canada The Importance of Education of Information Specialists
}

\author{
Lana Žaja \\ Croatian State Archives, Zagreb, Croatia \\ lanazaja@gmail.com
}

\begin{abstract}
Summary
The aim of this paper is to give insight, by a comparative analysis, of the publicly available documentation on the digital preservation of records in the Croatian State Archives, U.S. National Archives and Records Administration and Library and Archives Canada, and through the process of establishment of digital archives, point to the necessity of scientific and operational knowledge on information technologies and digital preservation. Methodologically presented activities and projects for the development of tools for digital preservation of records in digital archives, point out, above all, the potential education of archivists, who must be able to provide quality in-personal and on-line information service. Planning, strategy and the establishment of a digital archive are processes that, besides being organized and systematically implemented, require highly educated experts from multiple scientific areas. The use of international standards for the long-term data preservation that need to be secured within the defined guidelines and measures for the preservation process plan, which are to follow all components of the electronic file processing system in the archives, is presented. The directives on solving problems related to long-term storage and access to electronic archive material in today's environment should also be in accordance with the terms set by the legal frameworks. Given the importance of this issue, as well as its goals, the role of digital archives within state administration, e-government development and online access to information in databases, is crucial for scientific, operational and functional management of the system by experts who know how to ensure plan for development of policy on institution documents management.
\end{abstract}

Key words: long-term digital preservation, digital records, digital archives, international standards, archivist education, information specialists

\section{Introduction}

The introductory part should answer two key questions, namely: what exactly does the term 'longlasting digital archiving' mean and how does this term really differ from a regular backup of a document? The term 'archiving' nowadays covers several meanings in terms of the concept of sustainable digital archiving. The premise for what is not a long-term digital archiving, in the IT context, includes the following:

Long-lasting digital archiving is not a backup (it's not just about preserving the important file flow) Long-lasting digital archiving is not a hierarchical storage manager (migrating files to some of the formats in order to make place on the hard disk)

Long-lasting digital archiving is also not the last stage of data storage before oblivion or permanent loss of records.

Permanent archiving of a digital document implies a mandatory digital preservation plan that describes in detail the process of long-term preservation and preservation of digital data and metadata. The establishment of such a plan is primarily used to establish data sustainability and assess the reliability of techniques and tools to preserve a virtual collection. Maintaining access to data in its original form is certainly the cornerstone of digital preservation plans due to the constant evolution of technology. Computer hardware and software is slowly getting outdated and it is important to 
consider not only data retention, but also the preservation of their "support". ${ }^{1}$ The digital preservation plan consists of a series of actions to be carried out by the institution responsible for digital objects. The conservation plan takes into account the policy of conservation, legal obligations, technical and organizational constraints, user needs, conservation objectives, conservation context, assessment of conservation strategies and its outcomes, including the logical decision-making process. It also determines every action, along with the responsibilities, rules and conditions for their performance on the collection (conservation action plan). In case that this action, their implementation and their technical environment permit it, the action plan must be implemented on a continuous basis. Each conservation plan must include the following elements ${ }^{2}$ :

- identification which encompasses the definition of the plan and preparation of the project documentation

- the status of the plan (active, on hold, etc.)

- a description of institutional parameters

- description of the collection

- requirements for conservation management (budget, technical limitations, etc.)

- the cost of plan implementation

- the role and responsibility of the members responsible for the plan

- conservation action plan (in order to determine "when", "what", "where" and "how" is most commonly defined in the project itself).

There are several digital preservation rules and policies that can help institutions regulate and develop conservation strategies. Digital preservation policies are very conceptual, but they provide a practical guide in realization of conservation. The key to policy is, for example, the maintenance of manoeuvres that must be done to establish and enable free access. Besides, copyright compliance is an important policy in the implementation of the digital preservation plan. Digitized or born-digital material must be subjected to an assessment of the legal rights of reproduction and the law on secrecy. Although in many institutions, the development of preservation plan is often "ad hoc", it is possible to support its development by means of tools such as standards and policies defined by the international reference offices entities. By adopting a well-documented and standardized planning process, the durability of digital objects greatly improves. The fragility of digital objects lies in the fact that their IT environments are constantly changing, which is a problem in some of the preserved activities, for instance, in case of data migration. Although there are many tools for converting the object's format, it still possible that the initial appearance will change, for example, footnotes or hyperlinks could disappear. It is also possible to create an original environment of the object by emulation (process of a computer, device or program that mimics the function of another computer, device or program), but this method remains limited because it is difficult to extend it to a large number of digital objects. Moreover, this method is successful only during migration, but some object specificities may be lost due to inaccurate or incomplete mimicking competition, as well as the inability to restore essential aspects of the object by emulation. The main challenge is not only to preserve the data, but also to maintain access to that data in such a way as to preserve authenticity. Preserving object's authenticity is therefore a key issue in the development of the digital preservation program. That is way documenting the process of preservation is necessary, while transparency ensures the reliability of the contents of digital collections.

\section{Croatian State Archives}

The strategic plan from 2016. to 2018. encompasses the objective of securing the conditions for longterm preservation and usability of the record of the Croatian State Archives. ${ }^{3}$ The priority of this objective was to build the infrastructure and process of digital archive with relevant norms and existing practices, and the establishment of e-archives for the enforcement of legal regulations in relation to electronic records. For the aforementioned period, it was planned to prepare complete

\footnotetext{
${ }^{1}$ National Library of Australia. Guidelines for the Conservation of Digital Heritage. 2003. http://unesdoc.unesco.org/images/0013/001300/130071e.pdf. (20.7.5019.)

${ }^{2}$ Becker Hannes C., Guttenbrunner K.M., Strodl S. Systematic Planning for Digital Preservation: Assessment of Possible Strategies and Preservation of Building Plans. International Journal on Digital Libraries. 2009.

${ }^{3}$ Croatian State Archives. http://www.arhiv.hr. (25.7.2019.)
} 
project documentation and to provide sources for funding the construction of the digital archive structure. Chapter 5 of the strategic program of scientific research from 2015. to $2020 .^{4}$, in the planned topics of research under the title of the topics "Archives in the Digital Societies", includes the planning of the preservation of digital records. This research area includes several narrowly defined topics or subject-related researches related to managing electronic records, either with digitalisation of archive services or operation of archives in the communication space that is opened by digital technologies. There are two main research goals in this area. The first one is the upgrade or the ability of archives and other organizations to long-term protect of electronic documentation and to preserve its integrity, credibility and usability, and the second one is to improve methodologies and tools for designing and communicating archival content and services. The research is focused on the question of metadata scheme, development of catalogue rules and ontology in management of digital information resources. The archive has, together with main institutions in the field of museum and library activities and faculties which host an information science study, concluded an agreement on the development of new cataloguing rules, which should be based on harmonized or integrated concepts of presentation, structuring, description and search of information sources. The research involves analysing and evaluating different conceptual models and ontologies that are being offered today, with emphasis on those that are more present in the archives, libraries and museums. It also cover the issue of their interoperability, relationship to linked data and open data principles, as well as issues of standardized terminology and normative control and questions related to visualization of data. The second topic of research in this area is long-term preservation of integrity, credibility and usability of documentation in electronic form. The archive is part of one of the leading international projects in this are InterPARES ${ }^{5}$ Trust that is led by the University of British Columbia, within which technology, legal, business and social aspects are explored, as well as risks that can affect long-term preservation of electronic documents. Given that the long-term preservation of electronic documents largely depends on the characteristics of the information systems in which such documents arrive, the research is also focused on the issue of norms and procedures in the administration and the way in which they are implemented in information systems, that are used in business, with an emphasis on administration and public services. A particular goal in this segment of the research is the development of recommendations or guidelines for the revision of regulations and standards that currently regulate this area in Republic of Croatia and recommendations for the implementation of measures and activities relevant to the long-term preservation of integrity and credibility of electronic documents. The results of this research should enhance the ability of archives and creators of archival documents for long-term protection and preservation of the records in electronic form. Improving the quality of online catalogues and digital collections should facilitate their publication on relevant international portals. Contribution to the introduction of more modern norms and procedures in the office business of public service of the Republic of Croatia is expected. The importance of the strategic scientific research plan and its program has its main foundations in its own development by experts in the field of digital archives. Structuring this kind of program at the level of information studies leads to the creation of quality programs, the provision of information in real-time and the establishment of the necessary tools for managing the requirements of original digital records.

\section{Library and Archives Canada}

Library and Archives Canada ${ }^{6}$ (hereinafter referred to as LAC) collects, manages, maintains and provides permanent access to Canadian documentary heritage, while also serving as permanent repository of Canadian government records as well as publications and records of historical or archival value. LAC is the only organisation in the Canadian government with a national mandate for long-term preservation of records. This mandate is contained in the LAC legislation which places librarians and archivists in a status where they must have a knowledge o long-term preservation and disposal of documentary heritage. The LAC library and archives contain a wide range of textual,

\footnotetext{
${ }^{4}$ Strategic program of scientific research from 2015 to 2020. http://www.arhiv.hr/Portals/0/Dokumenti/Planovi\%20i\%20izvje\%C5\%A1\%C4\%87a/Strate\%C5\%A1ki\%20prog ram\%20znanstvenih\%20istra\%C5\%BEivanja\%202015.-2020.pdf?ver=2017-07-31-133703-747 (25.7.2018.)

${ }^{5}$ InterPARES Trust. https://interparestrust.org/ (23.4.2019.)

${ }^{6}$ Library and Archives Canada. http://www.bac-lac.gc.ca (6.8.2019.)
} 
visual, audio-visual and web content that support various software, hardware and operating systems in a multitude of formats that are sensitive to technological obsolescence, media degradation and record decay in general. The LAC's digital archive at the "Conservation Centre" serves as a storage for permanent digital collection of LAC. "Conservation Centre" contains only a part of digital collections that LAC has acquired over the years. Much bigger task is securing digital collections of documentary heritage, which should be preserved in a way that meets the LAC's mandate. In its "Strategy for program of digital reservation", LAC describes in three phases, a vision of digital document preservation:

Phase 1: Collecting information and factors of success of phase 1, Phase 2: Program development and factors of success of phase 2, Phase 3: Program implementation and factors of success of phase 3 .

Digital preservation is defined as "active management of digital content over time, in order to ensure permanent access". If this approach should be enabled, professional digital preservation staff must proactively monitor the information system and respond according to requests, in order to protect the digital heritage contact from technological obsolescence.

LAC is in compliance with the international standard ISO 14721: 2012, Reference model for the Open archive information system. OAIS reference model ${ }^{8}$ describes the functions and roles of the digital archive and helps to define the key elements that are required in the description of the digital preservation program site. LAC uses an OAIS reference model for defining the scope of its digital preservation program. Based on the definition of a model of lifecycle "Digital conditioning centre", digital preservation in LAC is part of a wider set of functions in the digital lifecycle of a record. The functions that are addressed in the DCC model are: downloading, preserving, storing and transforming. Although digital preservation is not directly responsible for the full digital lifecycle of a record, LAC provides guidance and advices for ensuring the integration of different components. The vision of digital preservation is that, within the end of 2024, LAC has a program of sustainable digital preservation that is in line with the international standard ISO $16363^{9}$ : revision and certification of reliable digital reserves. ISO 16363 is an international standard based on ISO $14721^{10}$. This is actually a checklist of delivered programs for digital preservation that provides a number of criteria for organizations that must meet these criteria in order to implement a reliable digital storage. Key elements in developing digital preservation program are defined in these international standards. To achieve this vision, LAC works on implementing sustainable technical solutions, such as the establishment of a collection management framework, in order to ensure systematic storage of digital collections. By shaping the future of digital preservation in LAC, this strategy provides a framework for managing and coordination of activities that are needed by organizations for achieving advanced maturity levels of digital information preservation systems. Each phase is actually a strategy divided into a set of interrelated results with multiple executive checkpoints for confirming the correctness of access. Phase 1 "Information collection" is based on the program platform, developed by the developer in cooperation with information specialists, as the basis for the overall development of the information system. The main activities are researching, identifying and documenting business needs and digital preservation issues. These activities are described as a fundamental exercise in defining the problem and specifying it. The results of the first phase identify the magnitude and scope of the digital preservation challenges of LAC, they define the need for technology and human resources and they provide a final analysis of non-compliance documentation to meet the stringed requirements of ISO 16363. The digital preservation business requirements, which were completed in June 2017, were used as a starting point for discussion and results, for streamlining business processes and developing business technology solutions to support the long-term preservation of digital funds. This document provides information on the size and scope of the required technology and it serves as a catalyst for the evolution of software solutions. It also provides managers with information that should help them to make investment decisions on infrastructure digital protection solutions. As part of the inventory of

\footnotetext{
7 Strategy for a digital preservation program. http://www.bac-lac.gc.ca/eng/aboutus/publications/Pages/strategy-digitalpreservation-program.aspx (10.6.2019.)

${ }^{8}$ Open Archival Information System OAIS.

https://www.oclc.org/research/publications/library/2000/lavoie-oais.html (23.4.2019.)

${ }^{9}$ ISO 16363. https://www.iso.org/standard/56510.html (23.4.2019.)

${ }^{10}$ ISO 14721. https://www.iso.org/standard/57284.html (23.4.2019.)
} 
digital collections, a gathering of collections profiles was created to better understand digital collections that LAC has acquired in the 1970s. These profiles allow the LAC to: quantify digital content that includes backdrops of record collecting, determine who is responsible for them, detect where they are located, determine their file formats and other collection characteristics, determine whether or not they are conserved and evaluate the risk of their permanent loss. These collection profiles describe the scope of work and the profile of professionals who need to be employed in the preservation of these digital assets, helping to guide future conservation planning. During this phase an analysis of political "gaps" is also being carried out, which means that future operational plans, procedures and priority practices for further development in the future should be identified. This analysis is managed by the LAC in establishing a formal policy framework to preserve Canadian digital documentary heritage. One of the key outcomes of Phase 1 is the development of guidelines that provide guidance on future development, as well as on implementation of the program. With describing the planned steps for building digital preservation capacity, this paper sets out the main planning activities to be fulfilled, the roles and responsibilities of information specialists, the sequence of their implementation and the overall time frame. The guidelines range from gathering information, technical solutions, managing digital collections, practices, plans and operational policies to the decision point at the end of Phase 1. The purpose of the aforementioned decision is to identify the features required by the information system in determining the size and scope of the problem. Actions and deliveries of this phase correspond to the requirements of digital preservation and analysis capabilities. The program development follows in Phase 2, which aims to develop additional precision on the estimates obtained in Phase 1, on the design of conservation programs. Until beginning of Phase 2, the size and scope of the problem should be understandable and clear, are the next steps are the design and delivery of digital preservation program capabilities. Technical solutions, based on the requirements for digital preservation completed in Phase 1, which have established the appropriate technology and infrastructure in the solution of digital preservation, in Phase 2 focus on developing analysis and design solutions. It also includes aspects of technical design for infrastructure of records storage, networks, platforms, applications, as well as interoperability and integration with other LAC information systems. The financial cost and the invested human knowledge, which is involved in this new business solution, are analysed. Ultimately, the options for managing the final decisions are presented. Based on inventory of digital collections, LAC in this second phase develops a digital collections management plan to allocate priority to digital collection formats, requirements for their conservation and the level of investment needed for each collection. One of the key activities of this phase is the implementation of more detailed sampling of collections for the assessment of corruption and data loss. It also develops technical specifications and standards for preserving different types of content. The plan of phase development practice, procedures and rules is issued in Phase 2 on the basis of analysis of a "difference" that is completed in Phase 1. By analysing all these decisions, a policy that has implications on price can be identified, such as the number of copies, storage and diversity of geographical locations. Workflow and procedures are further defined to allow unobtrusive "track" of records from receipt to retention and retrieval. Factor of success of Phase 2 is achieving clarity in all its program directions. LAC defines what makes scalable services and infrastructure for the program. It sets the level of investment in the required technology, infrastructure and resources, as well as cost models. The knowledge base on the scope of digital content that needs to be preserved, the need for required staff, the billing priorities, the preservation of new collections, the cost of delivering the program and the appropriately allocated budget levels are implemented in this Phase 2. By summarizing the above mentioned, the following can be concluded: steps in Phase 2 are: development of programs, technical solutions, management of digital collections, practices, plans and operational policies and decision-making at the end of Phase 2. The purpose is to develop potential technological solutions based on business requirements developed in Phase 1 , as well as to provide evidence on the stated concept and to evaluate the required technological investments. Actions and deliveries depend on technical analysis and design of technical solutions for defining appropriate hardware and software technologies and all other components required for long term preservation. Phase 3 is the implementation of the program, in which the LAC is fully ready to launch program implementation because it has a defined vision, established interinstitutional obligations, management support, organizational capacity, consistent workflow and approved funding for the program. By the end of the Phase 3, LAC achieves its goal of a sustainable digital preservation program and a reliable 
digital repository in line with national and international best practices and standards. Phase 3 success factors are project completion of technical infrastructure, with well-equipped and fully formed business information, with which the design will be implemented. The result of all of the abovementioned phases is a fully functional technological solution for supporting digital preservation. Based on the decision made in the database management plan, in Phase 2 LAC is equipped with the necessary tools and decision-making infrastructures in order to perform priorities of digital preservation of all collections. The collection management document must be refreshed regularly, as other new and old collections arrive. Given that digital collections management is implemented, a collection management plan becomes a key part of conservation planning and administrative workflow. The LAC implements ISO 16363, auditing and certification of trusted digital repositories, in order to evaluate the progress of its program implementation. During this revision, the approach that should satisfy audit and certification organization team is determined. Due to the large amount of digital collections, at the level of the required documentation, the LAC must fulfil the formal certificate with the auditor from the "third" (neutral) side, who is accredited according to ISO $16919^{11}$. Other approaches may include informal certification by re-self-evaluation. Comprehensive Phase 3 steps can be said to be: implementation of programs, technical solutions, digital database management, practices, plans and operational policies. The ultimate purpose of this Phase is to implement business solutions. Action strategies and deliverables provide a digital preservation solution, as well as the implementation of a scalable digital preservation solution. The digital preservation program strategy is regularly refreshed, when delivering each of the specified phases that are completed, or when implementing a digital preservation program that is integrated within the organization. LAC's strategic approach to digital preservation is a dynamic development program that is in the process of maturation. Program plans and conservation services are regularly reviewed and updated to continuously align with their organizational mandate and strategic goals. Permanent improvement of the services for solving inherited, new and original digital content is part of the organizational planning, streamlined according to technical and other models of service provision in the digital ecosystem. LAC on its website points out that, with this investment strategy, it is most important to show stability of purpose and professionally trained commitments, with its obligations of digital preservation in order to ensure the survival of the national documentary heritage. The consequences and costs of human resources in terms of inaction, would be a failure in nonfulfillment of their statutory mandate, as well as obligation towards Canada's citizens, and ultimately, in the worst case, the loss of national content of digital heritage.

\section{U.S. National Archives and Records Administration}

U.S. National Archives and Records Administration ${ }^{12}$ (hereinafter referred to as NARA) identifies, stores and provides access to large number of archive materials of the US government. NARA takes care of preserving these records in order to protect civil rights, ensure government accountability and documents. The archive fund covers more than 13 billion pages of unique documents, electronic materials, maps, charts, photography, artefacts, as well as film, sound and video records. Records stored by NARA belong to the public, and the main mission is to focus on openness to the public, educate the public in participating in various digital programs, and strengthen national democracy through public open access to all state records. The preservation of NARA's digital records, including copies for public use and digital surrogates, was created through the project scope which conducts digitalization procedures. NARA advocates the preservation and maintenance of access to the contents of all original digital records and digital surrogates that are in its possession and for which archivists determine that they contain sufficient historical or other values that ensure continued conservation by the US Government. The digital preservation implies continuous use of records, which is considered essential and viable for the purpose of creating digital materials. NARA uses several key strategies to enable the effective preservation of digital content, knowing that these strategies have to be flexible and adapted to current changes in benchmarks, technology and standards. The main goal of all strategies is to reduce risk and achieve best practice for digital preservation and maintenance of access to digital content. The first strategy involves combining

\footnotetext{
${ }^{11}$ ISO 16919. https://www.iso.org/standard/57950.html (24.4.2019.)

${ }^{12}$ National Archives and Records Administration of the United State of America. https://www.archives.gov/. (6.8.2019.)
} 
documentation of standards and procedures. By documenting internal standards for the creation of digital surrogates, guidelines for the creation of digital surrogate agencies, as well as the minimum metadata and the preferred file formats for electronic records transmitted to NARA are enabled. By encouraging the use of open standards and accepted on consensus of information and digital professionals, the future access and preservation of the entire lifecycle of digital preservation of records are made easier. The second strategy sets priorities and is focused on approaching the risks of setting priorities for digital protection and performing the schedule of default digital activities. The third strategy manages files that store digital content in a trusted repository of digital objects, thus allowing continuous management, as well as accessing content over the entire lifecycle of the record. NARA's repository is based (as is the Canadian archive, as previously described) on the Open Archival Information System Reference Model (OAIS): ISO 14721: 2012: A reliable digital repository whose main mission is to provide a reliable, long-term approach to managed digital resources to their separate community, now and in the future (OCLC, Trusted Digital Repositories: Attributes and Responsibilities, 2002). NARA reduces the number of file formats that need to be actively managed, by standardizing files in selected formats, while retaining authentic features of original format. The fourth strategy is the importance of authenticity, which refers to the credibility of record as an accurate representation of the original. Insurance of the authenticity is documented according to OAIS model. The fifth strategy provides guidelines for metadata of conservation. By joining permanent digital identifiers and capturing metadata about preserving each digital object, data is stored as computer files in application software that allows searching. This software also helps to keep digital records over time, with manual (semiautomatic) and automatic preservation procedures. Preserving metadata ensured the preservation of key contextual, administrative, descriptive and technical information, along with a digital object. The sixth strategy describes organizational relationships that emphasize the importance of active participation in local, national and international digital preservation meetings in order to exchange information and experience in seeking further guidance and establishing cooperation in addressing digital protection issues. This engagement helps identify new risks, practices, as well as a description of new standards that continually strive to improve the digital archives program. By engaging information professionals who know how to manage information technologies, understanding of the needs of digital preservation, development of new technical tools and program-information systems are secured. Digital conservation activities should continuously be the subject of ongoing evaluation, using appropriate audit-based assessment tools, certificates and/or national standards for conservation of digital governance, which measure the ability, stability and maturity of digital preservation programs. Stable digital preservation is achieved through the digital protection infrastructure, which ensures data integrity, formats and their sustainability and information security. Digital conservation infrastructure such as hardware, software, networks, storage, associated equipment with related development tools, development tools, testing, management, control, management and support for information technology are important constituents of digital preservation. Warehousing or storage of data is one of the most important steps in determining the system's network capabilities and tools for creating, processing and managing active files of original digital files and digital surrogates. The next step is to process regular professional supervision, to update the entire system and tools that NARA develops for the purpose of developing its own business processes, and which need to be accessible for the storage of the contents of original digital files and digital surrogates. These replications include one storage copy in another environment, preferably in a remote geographical location that includes replications that can be provided through an e-service "NARA Cloud". The tools ${ }^{13}$ for determining forensic identification and formatting of records include the identification of file formats (identification of technical files), validation of the format (confirmation of the file compliance with documented format specifications) and extraction of technical metadata (documentation on file creation, including applications and operating systems) used for support in assessing the risk of outdated format and publishing files to users using the appropriate application or browser in the default context. Tools for transformation of file formats serve to execute migration of files over time, as formats become obsolete and therefore risky. Standardized workflow processes for linking original digital and digital surrogate files with

${ }^{13}$ NARA's Adoption and Management of Cloud Computing. https://www.archives.gov/files/oig/pdf/audit-report-17-08.pdf (20.10.2019.) 
record identifiers and metadata, provide primarily appropriate IT storage spaces and cloud-based access servers. Data integrity is based on records of all incoming files with degraded events, as well as all subsequent life cycles, such as transformations of the format of moving files with different revisions. Downloading a file is a process that must involve scanning "malicious" software and checking the file's validity. Checking the validation of files refers to checking in which the file has not been changed from the previous state. Copying content from a physical medium must include the use of "blocker", i.e. devices that prevent accidental damage of content on physical media. Furthermore, it is necessary to perform an annual check of all samples of digital electronic records and digital surrogates stored in the storages, including checking if they are not supported, in order to correct and/or replace the errors with other files as fast as possible. It is necessary to implement a retrograde quarterly revision of the $\log$, in order to verify that the files in the repositories have remained unchanged and have not been corrected over time. Ultimately, it is necessary to carry out an annual check of all media, which in its workflow contains permanent records on permanent storage. Before the media (which contain permanent records) "reach" ten years, they are copied to tested and checked new electronic media. Format and media sustainability are the main features for checking formats and files at the download site. Characterization refers to the identification and description of the technical characteristics such as the original file environment. Technical metadata is recorded. Validation refers to the confirmation that the file should match the expected characteristic in that type of record. By creating action plans for file formats that identify formats of other files, the necessary action is enabled, for those formats that are no longer viable or not available through the current software. Then, it is necessary to create standardized versions of the files that are not in a risky format, as it is defined with plan in the previous action strategies for file formats. Standardization is converting all files into certain types of file formats, as for example, e-mail, jpeg, which will be sustainable over longer period of time. By analysing the file formats and media formats, potential future obsolescence can be permanently determined. By performing migration of automatic and manual formats or other conservation activities, based on the file formats action plans, systematic monitoring of large digital conservation files in technological environment is set up. Action plans include warning signs for formats, media and/or equipment that become potentially outdated and are no longer viable. Information security should allow physical access to: media, information systems, and data entry and processing services, which include reading, writing, and authorization in folders and files on different servers. The importance of insurance is that no one can access all the files. A file action system log must also be maintained, including deleting and modifying actions. From these procedures and guidelines, it is evident that there are many key factors that enable and contribute to the ultimate success of this digital protection strategy. Certainly, the critical factors that NARA has to deal with to fulfil its goals, which is education and the level of education of professional staff, must be highlighted. With all these strategies, NARA confirms that the digital preservation is a significant business management process that goes through several layers of business units requiring business and professional excellence. A special human resources development plan has been designed to support all of the above-mentioned functions, which are the man backbone and infrastructure of all of the above-mentioned information technologies. The planning process is crucial here because it identifies the needs of the infrastructure to support digital preservation which includes information systems, tools, storage, network capacity, data integrity and safety of the information system. By documenting all of the mentioned relevant management processes, in the context of the management, including those for predicting record storage, network capability, planning and implementation of additional capacities and refreshment of technology, the main guidelines for creators and record holders are given. NARA continues to develop and publish guidelines for format and metadata standards, in order to ensure the sustainability of original digital data and digital surrogates. The document "Preservation of electronic records: Strategy for the preservation of digital archive materials" "14 was published on 8 June 2017.

\footnotetext{
${ }^{14}$ Preserving-Electronic-Records-History. https://www.archives.gov/files/Preserving-Electronic-RecordsHistory.pdf (6.8.2019.)
} 


\section{Conclusion}

Digital preservation of electronic records for contemporary archivists and digital archives brings changes on multiple levels, and the differences are visible not only to the degree of development of information systems and financial possibilities, but also to the level of education of professionals who manage complex digital systems. Using standards in digital preservation helps archives to create information systems and services that are safe and reliable. It is transparent that standards help archives to increase productivity, while reducing and eliminating errors in digital archives systems. Also, they allow direct alignment of data with metadata of different types of records. Standards ensure the protection of end-users of products and services, thus allowing certified products to meet the minimal criteria of standard set at the international level. In the digital archives of the USA and Canada, active engagement in the development of e-government has been evident, and the archival strategic role is becoming increasingly important. Croatian State Archives should, through networking with state-level administrations, introduce new additional favourable digital services for private and legal persons, as well as to increase the interest in adopting new continuous knowledge in the field of digital technology development. According to the LAC's definition, digital conservation involves "actively managing digital content over time in order to ensure consistent access to records". From this definition, it can be concluded that in the organization of the archive all employees should be proactively and continuously educated, and within the archive there should be special professional services that monitor and, if necessary, intervene for 24 hours a day at all levels of the system, in seeking to protect the digital heritage content from technological obsolescence and/or accidental loss of records. By customizing traditional archival practices in the management of electronic records and manuscripts, information professionals need to be able to select the appropriate tools to use in analysis and processing of digital records and manuscripts. Creative design and development of work processes for accessing and processing digital records and manuscripts requires from repository managers and archivists to have professional expertise and scientific responsibility for the arrangement, description and availability of electronic records. The role of technological development dictates the gathering of world experts from different fields of knowledge in addressing for digital archives to keep pace with the numerous developmental reforms brought by the technological future.

\section{References}

Bralić, V., Kuleš, M., Stančić, H. (2017). A model for long-term preservation of digital signature validity: TrustChain // INFuture2017 Proceedings: The Future of Information Sciences / Atanassova, I., Zaghouani, W., Kragić, B., Aas, K., Stančić, H., Seljan, S. (eds.). Zagreb: Department of Information and Communication Sciences, Faculty of Humanities and Social Sciences, University of Zagreb, Croatia, 89-103

Croatian State Archives. http://www.arhiv.hr. (25.7.2019.)

Duranti, L. (2000). Arhivski zapisi: teorija i praksa. Zagreb: Hrvatski državni arhiv. International Organization for Standardization (ISO). https://www.iso.org/standard (24.7.2019.)

ISAAR. (2011). ISAAR (CPF): International Standard Archival Authority Record for Corporate Bodies, Persons and Families, 2nd Edition. (2011). http://www.arhiv.hr/Portals/0/ISAAR\%28CPF\%29_2_Izd_Hrv_1.pdf (1.8.2019.)

ISAD $(G)$ (2011). General International Standard Archival Description - Second edition. http://www.arhiv.hr/Portals/0/ISAD_\%28G\%29_2_Izd_Hrv.pdf (1.8.2019.)

ISO 14721, ISO 16363, ISO 16919. http://www.iso16363.org/ (19.10.2019.)

Library and Archives Canada. http://www.bac-lac.gc.ca (6.8.2019.)

National Archives and Records Administration of the United State of America. https://www.archives.gov/ (6.8.2018.)

PREMIS Preservation Metadata Maintenance Activity. US Library of Congress. Retrieved. (2013). https://www.loc.gov/standards/premis/ (2.8.2019.)

Stančić, H. (2017). Obrazovanje arhivista // Arhivi u Hrvatskoj - (retro)perspektiva / Babić, Silvija (ed.). Zadar: Hrvatsko arhivističko društvo, 37-49

Stančić, H., Rajh, A., Brzica, H. (2015). Archival Cloud Services: Portability, Continuity, and Sustainability Aspects of Long-term Preservation of Electronically Signed Records = Les services d'archivage dans un nuage informatique: Portabilité, continuité et durabilité: Aspects de la conservation à long terme des documents signés électroniquement. // Canadian journal of information and library science 39, 2, 210-227

Stančić, H., Rajh, A., Jamić, M. (2017). Impact of ICT on Archival Practice from the 2000s Onwards and the Necessary Changes of Archival Science Curricula // Proceedings of the 40th Jubilee International Convention on Information and Communication Technology, Electronics and Microelectronics MIPRO 2017 / Biljanović, Petar (ed.). Rijeka: Croatian Society for Information and Communication Technology, Electronics and Microelectronics - MIPRO 918-923 
INFuture2019: Knowledge in the Digital Age

Strategic program of scientific research from 2015 to 2020.

http://www.arhiv.hr/Portals/0/Dokumenti/Planovi\%20i\%20izvje\%C5\%A1\%C4\%87a/Strate\%C5\%A1ki\%20program\%2 Oznanstvenih\%20istra\%C5\%BEivanja\%202015.-2020.pdf?ver=2017-07-31-133703-747 (25.7.2019.)

Strategy for a digital preservation program. http://www.bac-lac.gc.ca/eng/aboutus/publications/Pages/strategy-digitalpreservation-program.aspx (10.6.2019.) 